\title{
Neuroendocrine effects in printing workers exposed to toluene
}

\author{
Bengt-Göran Svensson, Gun Nise, Eva Marie Erfurth, Håkan Olsson
}

\begin{abstract}
The effect of exposure to toluene on plasma concentrations of testosterone, prolactin, luteinising (LH) and follicle stimulating (FSH) hormones was investigated in 47 rotogravure printers (time weighted average air toluene below $80 \mathrm{ppm}$; blood toluene concentration post-shift 0.19-7.99 $\mu \mathrm{mol} / 1)$ and compared with a reference group. Increasing exposure concentrations of toluene (concentrations $<5$ to $>45 \mathrm{ppm}$ ) were significantly associated with decreasing plasma concentrations of LH (tau $=-0.21, p=0.003)$ and testosterone (tau $=$ $-0.25, p=0.02)$. No correlation was found between cumulative exposure (ppm $\times$ years) and plasma hormone concentrations. The associations with exposure were present even when nine printers with heavy alcohol consumption were excluded. The study indicates an effect of low toluene exposure on the hypothalamus-pituitary axis, with a secondary decrease in testosterone secretion.
\end{abstract}

Toluene has, like many other organic solvents, neurotoxic effects. Acute effects on the central nervous system (CNS) are well known ${ }^{12}$ and residual CNS damage is suspected after long term exposure to high concentrations of toluene. ${ }^{3}$

Adverse effects of 2,5-hexanedione, which is the neurotoxic metabolite of the industrial solvents nhexane and methyl n-butyl ketone, have been found in the hypothalamus. It causes axonal degeneration in the mamillary body and other parts of the hypo-

Department of Occupational and Environmental Medicine

B-G Svensson

Department of Medicine

E M Erfurth

Department of Oncology, University Hospital, S-221

85 Lund, Sweden

H Olsson

Department of Occupational Medicine, General Hospital, Malmö

G Nise thalamic area, as well as in other central and peripheral nervous structures. ${ }^{4}$

Subacute exposure of rats to toluene, xylene, and ethylbenzene can produce changes in dopamine and noradrenaline concentrations and turnover in various parts of the hypothalamus. ${ }^{56}$ In this area catecholamine neurotransmission is important for the regulation of pituitary hormone secretion..$^{7-10}$ To investigate if the secretion of pituitary hormones was affected in men exposed to toluene, the plasma concentrations of testosterone $(\mathrm{P}-\mathrm{T}$ est), prolactin $(\mathrm{P}-$ PRL), luteinising hormone (P-LH), and follicle stimulating hormone (P-FSH) were measured and compared with those of a reference group without exposure to toluene.

\section{Subjects and methods SUBJECTS}

Forty seven men from two rotogravure printing companies and exposed to toluene have been studied. One of the companies (A) is very modern and has low exposure. The other (B) has an older printing hall with higher toluene concentrations in the air. Most of the printers have been exposed to toluene in printing offices for many years. The mean duration of employment was 18.4 (range 4-33) years for the 28 men from company $A$ and 14.5 (range 3-39) years for the 19 men from company $B$.

Twenty three workers from a metal industry and 23 craftsmen from hospital workshops were used as referents. None of these were exposed to organic solvents.

The mean age for the exposed group was 44.4 (range 23-62) years, and for the referents 43.5 (range 20-61) years.

A thorough clinical examination was carried out on each printer. Medical records from the local hospital, questionnaires, and personal interviews were used to obtain information on relevant life style and health state. Individual alcohol consumption was estimated carefully. Printers were regarded as "high alcohol consumers" when one or more of the following criteria were met: medical records indicating alcohol related disease, the presence of significant ethanol concentrations $(>0.5 \mathrm{~g} / \mathrm{l})$ in blood samples collected during working hours, or estimated weekly alcohol 
consumption above $250 \mathrm{~g}$. None of the printers were on any medication known to interfere with liver function or hormone concentrations.

\section{EXPOSURE}

\section{Present exposure}

Air concentrations of toluene were measured by personal sampling with a technique described by Övrum. ${ }^{11}$ Each working shift was followed for a week, and about half of the members of the shift were monitored each working day. The workers wore a personal sampler, with which samples were continuously taken from the ambient air at $\mathbf{3 0}$ minute intervals. Consecutive samples were used to monitor as much working time as possible. The sampler (Linder Gaspirator, Instrument AB Lambda, Sweden) collected air from the breathing zone, with air flow maintained at a constant speed for 30 minutes, through a Teflon capillary tube into a $30 \mathrm{ml}$ all glass syringe. The samples were immediately analysed with a portable gas chromatograph (GLC, Varian, type AID 511) with a flame ionisation detector. Standard gases were prepared by adding known amounts of toluene to clean air. As calculated from 25 duplicate determinations (toluene concentrations of $67-335 \mathrm{mg} / \mathrm{m}^{3}$ ), the error of the method was $1 \cdot 1 \%$ of the mean value.

Area samples and spot samples from various operations were also collected with the same technique.

Venous blood samples from each printer were taken on Monday pre-shift and twice on Thursday (pre- and post-shift) in a working week and analysed for toluene. These analyses were made with the head space technique, using ethylbenzene as internal standard on a gas chromatograph (Varian model 3700) equipped with flame ionisation detection. Standards were made from venous blood by adding known amounts of toluene. The detection limit was 0.05 $\mu \mathrm{mol} / 1$. The error of the method was $4 \%$, for blood toluene concentrations of 0.20 and $3.8 \mu \mathrm{mol} / 1$.

An average exposure concentration during working days was calculated for each printer. The bases for these estimates were: (1) the numerous analyses of individual atmospheric samples, especially from those occasions (42 at company A; 31 at company B) when workers were monitored for more than $75 \%$ of a full working day of eight hours. (2) Detailed and extensive information on working procedures and working tasks for each worker obtained during the two full working weeks spent by the study group in each company. (3) Results from the analyses of toluene in blood and knowledge of the association between concentrations in air and blood ${ }^{1213}$ were used to validate the results from the exposure estimates and to check for possible dermal exposure.

The results from the estimates of average exposure for each worker made it possible to assign all except one exposed subject into one of six different classes of exposure, each with an estimated air concentration (fig 1) (this differentiation was done by one of us (GN) without knowledge of the results of the hormone analyses).

\section{Historical exposure}

Past exposure was evaluated from the results of the measurements described above, study of all available material concerning the working environments, and through interviews with workers and foremen about working conditions (the method used has been described in detail earlier ${ }^{14}$ ). Table 1 gives estimated exposure concentrations in the past. Also, a cumulative exposure index was calculated for each subject as the sum of exposure concentrations $x$ duration of employment.

\section{HORMONE ASSAYS AND LIVER FUNCTION TESTS}

Venous blood samples were drawn from the exposed subjects and the referents on a day in the middle of a working week, between 10.00 am and $1.00 \mathrm{pm}$. A part of each sample was sent to the Department of Clinical Chemistry at the University hospital in Lund for analysis of serum bilirubin concentrations and alkaline phosphatase (S-ALP), $\gamma$-glutamyl transpeptidase (S-GT), aspartate and alanine aminotransferase (S-ASAT and S-ALAT) activities by routine clinical methods.

Plasma samples for the hormone analyses were stored at $-20^{\circ} \mathrm{C}$. The P-FSH, P-LH, P-PRL, and total P-Test were analysed in plasma with radioimmunoassay (RIA) techniques. ${ }^{15} 16$ Samples from exposed subjects and referents were mixed in each analytical series. The normal reference ranges for $P$ FSH, P-LH, P-PRL, and P-Test were 0.3-2.7 $\mu \mathrm{g} / \mathrm{l}$, $0 \cdot 3-1 \cdot 4 \mu \mathrm{g} / 1,2-12 \mu \mathrm{g} / 1$, and 6-30 $\mathrm{nmol} / 1$ respectively.

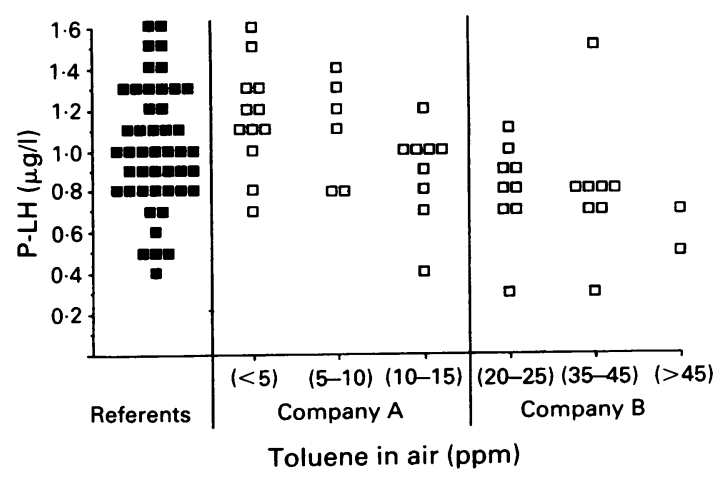

Figure 1 Plasma concentrations of luteinising hormone (P-LH) for referents and subjects exposed to toluene, assigned to six different classes of average exposure. Approximate ranges of toluene in air (ppm) for each class are indicated in parentheses. 
Table 1 Estimated historical exposure in the two companies for different periods

\begin{tabular}{lll}
\hline & \multicolumn{2}{l}{ Air concentration $(\mathrm{ppm})$} \\
\cline { 2 - 3 } Year & Company $A$ & Company $B$ \\
\hline 1955 & 150 & 450 \\
$1956-57$ & 450 & 450 \\
$1958-68$ & 450 & 300 \\
1969 & 250 & 300 \\
$1970-72$ & 250 & 240 \\
$1973-74$ & 160 & 240 \\
$1975-76$ & 160 & 100 \\
1977 & 160 & 65 \\
$1978-79$ & 80 & 65 \\
$1980-$ & 12 & 37 \\
\hline
\end{tabular}

STATISTICS

Non-parametric statistical methods (Mann-Whitney U-test, Kendall rank correlation coefficients $(t)$ ) were used. Kendall partial rank correlation coefficients $\left(t_{\mathrm{xy.z}}\right)^{17}$ were used to study the influence of age on doseresponse relations. Statistically significant denotes $p$ $<0.05$ and $p$ values are two tailed.

\section{Results}

PRESENT EXPOSURE

Air concentrations of toluene varied considerably from day to day and even within a working shift (fig 2). On a "good" day concentrations could stay well below the Swedish threshold limit value (TLV) for toluene ( $80 \mathrm{ppm}$ at the time of the sampling) during a whole shift. On the other hand, a "bad" day could mean air concentrations of more than $100 \mathrm{ppm}$ on several occasions.

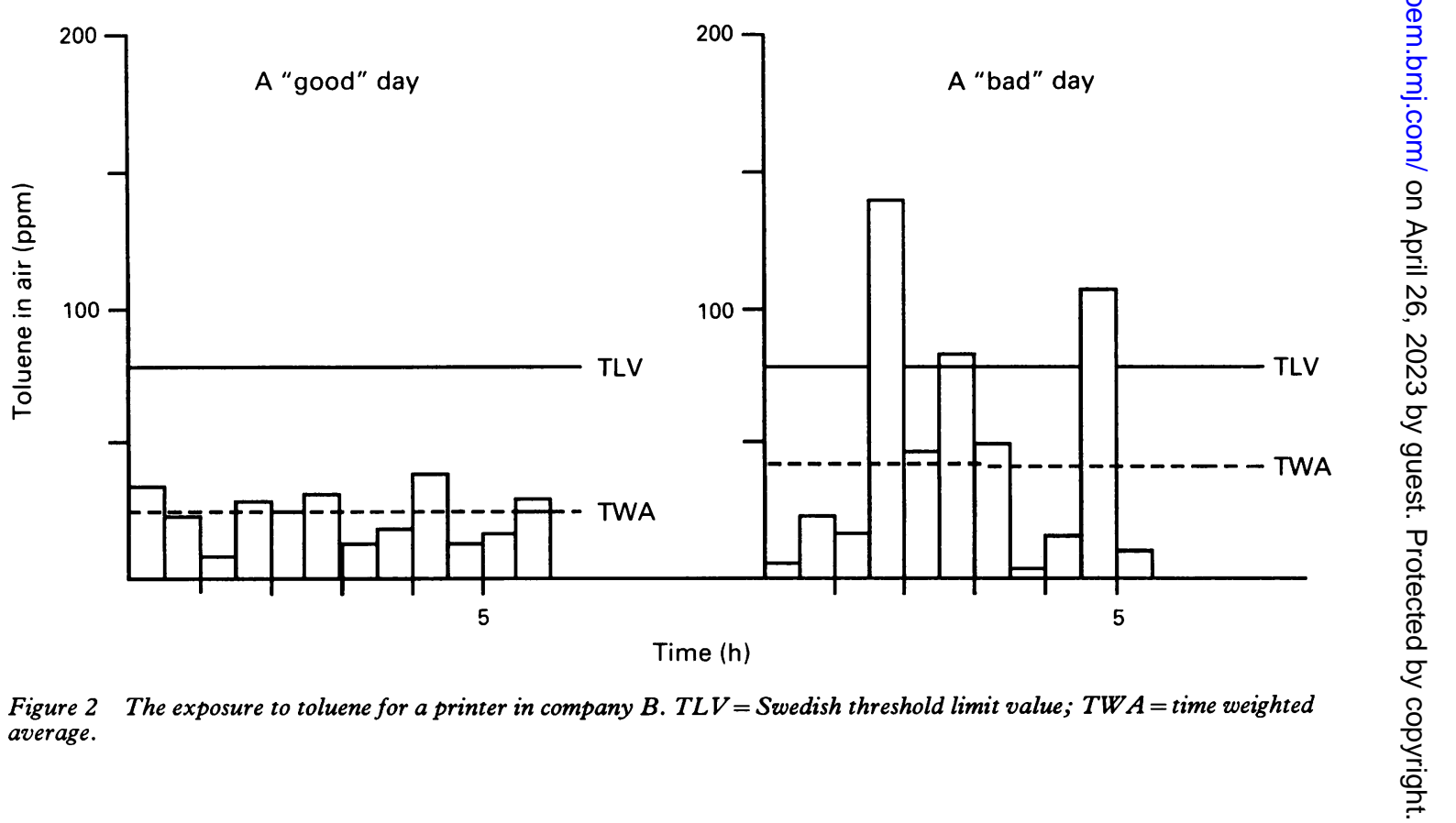

Figure 2 The exposure to toluene for a printer in company B.TLV=Swedish threshold limit value; TWA=time weighted average.

The average measured air concentration for printers in company A was calculated as $11 \mathrm{ppm}$ (range between individual subjects for all sampling periods 1-108 ppm) and in company $B$ at $47 \mathrm{ppm}$ (range 6$142 \mathrm{ppm}$ ). If only results from measurements covering more than $75 \%$ of a full working day were considered, an exposure level above $25 \mathrm{ppm}$ was found only once in company $A$. The other results had a median of $7 \mathrm{ppm}$. The corresponding results from company B were none below $20 \mathrm{ppm}$, and about three quarters of the results above $25 \mathrm{ppm}$ (median 33 $\mathrm{ppm}$ ). Using the estimated average exposure concentrations for each worker, all the workers from company A were placed in one of the three lower exposure categories, whereas those from company B fell into the higher three exposure categories.

Toluene concentrations in blood ranged from $0.05-0.83 \mu \mathrm{mol} / 1 \mathrm{pre}-\mathrm{shift}$ on Mondays and $0.19-8.0$ $\mu \mathrm{mol} / 1$ post-shift on Thursdays (table 2). Values for the pre-shift on Thursdays were higher than those for pre-shift on Mondays, indicating an accumulation during the working week.

HISTORICAL EXPOSURE

A cumulative exposure index for toluene could be estimated for 45 out of the 47 exposed subjects. The median was $2896 \mathrm{ppm} \times$ years and the range 4811216.

\section{HORMONES}

Influence of present exposure

There was no statistically significant differences in PLH between exposed workers and referents (table 3; 
Table 2 Toluene concentrations in pre-and post-shift blood samples ( $\mu \mathrm{mol} / \mathrm{l}$ )

\begin{tabular}{|c|c|c|c|c|c|c|}
\hline & \multicolumn{3}{|c|}{ Company $A$} & \multicolumn{3}{|c|}{ Company $B$} \\
\hline & \multirow{2}{*}{$\begin{array}{l}\text { Monday } \\
\text { Pre }\end{array}$} & \multicolumn{2}{|l|}{ Thursday } & \multirow{2}{*}{$\frac{\text { Monday }}{\text { Pre }}$} & \multicolumn{2}{|l|}{ Thursday } \\
\hline & & Pre & Post & & Pre & Post \\
\hline $\begin{array}{l}\text { Median } \\
\text { Range }\end{array}$ & $\begin{array}{l}0.21 \\
0.14-0.83\end{array}$ & $\begin{array}{l}0.31 \\
0.14-1.83\end{array}$ & $\begin{array}{l}0.8 \\
0.19-3.05\end{array}$ & $\begin{array}{l}0.07 \\
0.05-0.40\end{array}$ & $\begin{array}{l}0.40 \\
0.08-0.86\end{array}$ & $\begin{array}{l}2 \cdot 70 \\
0.66-7.99\end{array}$ \\
\hline
\end{tabular}

Table 3 Serum hormone concentrations (medians) in different age groups

\begin{tabular}{|c|c|c|c|c|c|c|c|c|c|c|}
\hline \multirow[b]{2}{*}{ Age } & \multicolumn{5}{|c|}{ Exposed workers } & \multicolumn{5}{|c|}{ Referents } \\
\hline & No & $\begin{array}{l}L H \\
(\mu g / m l)\end{array}$ & $\begin{array}{l}F S H \\
(\mu g / m l)\end{array}$ & $\begin{array}{l}P R L \\
(\mu g / m l)\end{array}$ & $\begin{array}{l}\text { Test } \\
(\text { nmol/l) }\end{array}$ & No & $\begin{array}{l}L H \\
(\mu g / m l)\end{array}$ & $\begin{array}{l}F S H \\
(\mu g / m l)\end{array}$ & $\begin{array}{l}P R L \\
(\mu g / m l)\end{array}$ & $\begin{array}{l}\text { Test } \\
(\text { nmol/l) }\end{array}$ \\
\hline $\begin{array}{l}<40 \\
40-50 \\
>50 \\
\text { All }\end{array}$ & $\begin{array}{l}14 \\
14 \\
19 \\
47\end{array}$ & $\begin{array}{l}0.8^{\star \star} \\
0.9 \\
1.0 \\
0.9\end{array}$ & $\begin{array}{l}0.4^{\star} \\
0.9 \\
1.2 \\
0.9\end{array}$ & $\begin{array}{l}3.3 \\
3.0 \\
2.5 \\
3.0\end{array}$ & $\begin{array}{l}13.8 \\
16.0 \\
15.9 \\
15.8\end{array}$ & $\begin{array}{l}17 \\
11 \\
18 \\
46\end{array}$ & $\begin{array}{l}1.1 \\
0.9 \\
0.9 \\
1.0\end{array}$ & $\begin{array}{l}1 \cdot 0 \\
1 \cdot 1 \\
1 \cdot 2 \\
1 \cdot 1\end{array}$ & $\begin{array}{l}4 \cdot 2 \\
2 \cdot 9 \\
3 \cdot 2 \\
3 \cdot 2\end{array}$ & $\begin{array}{l}17 \cdot 1 \\
15 \cdot 4 \\
15 \cdot 1 \\
16 \cdot 0\end{array}$ \\
\hline
\end{tabular}

${ }^{\star} \mathrm{p}<0.05 ;{ }^{\star \star} \mathrm{p}<0.01$ when testing exposed workers $v$ referents.

fig 1). When the groups were stratified for age, a difference was found for P-LH in the youngest group ( $<40$ years; $p=0.004 ;$ table 3 ).

When data from exposed workers and referents were analysed together, there was a significant negative association between estimated present exposure and P-LH (tau $=-0.21, p=0.003$; fig 1 ). This association was more pronounced within the exposed group (table 4). The association was not significantly affected when the Kendal partial rank correlation coefficient was calculated between present exposure and hormone concentrations with age as the variable kept constant (table 4).

No statistically significant difference was found in P-FSH between printers and referents (table 3; fig 3). A difference was, however, found in the age group below $40(p=0.04$; table 3 ). Rising present exposure was associated with decreasing hormone concentrations (tau $=-0.17, p=0.02$; fig 3 ). In the group of exposed workers only, this association was stronger (table 4). When the influence of age was considered, with calculation of the partial rank correlation coefficient, the association between present exposure and P-FSH was weakened (table 4). There was no significant difference in P-PRL between exposed workers and referents (table 3 ). P-Test in exposed workers did not differ significantly from the referents (fig 4; table 3). In the whole population under study, we found a significant negative association between present exposure and $\mathrm{P}$-Test (tau $=-0 \cdot 15, \mathrm{p}=$ 0.05 ; fig 4). The corresponding rank correlation coefficient within the exposed group was stronger and this correlation was not significantly affected when a possible influence of age was considered (table 4).
INFLUENCE OF CUMULATIVE EXPOSURE

The cumulative exposure index for toluene was significantly associated with P-FSH (tau $=0.31, \mathrm{p}=$ 0.003 ). The Kendall partial rank correlation coefficient between P-FSH and the cumulative exposure index (age kept constant) was $0 \cdot 11$, thus indicating a large influence of age upon the association with cumulative exposure.

There was no association between P-LH, or PPRL, or P-Test on the one hand, and cumulative exposure on the other.

Table 4 Kendall rank correlation coefficients ( $t$ ) for the different hormone concentrations with exposure and age respectively and Kendall partial rank correlation coefficients for exposure $\left(t_{x y . z}\right)$ with the variable age adjusted for

\begin{tabular}{|c|c|c|}
\hline & \multicolumn{2}{|l|}{ Exposed group } \\
\hline & $A l l(n=47)$ & $\begin{array}{l}\text { Restricted }+ \\
(n=38)\end{array}$ \\
\hline $\begin{array}{l}\text { P-LH/exposure } \\
\text { P-LH/age } \\
\text { P-LH/exposure, age, } t_{x y . z}\end{array}$ & $\begin{array}{l}-0 \cdot 47^{\star \star \star} \\
0 \cdot 25^{\star} \\
(0 \cdot 42)\end{array}$ & $\begin{array}{l}-0 \cdot 46^{\star \star \star} \\
0 \cdot 24^{\star} \\
(0 \cdot 42)\end{array}$ \\
\hline $\begin{array}{l}\text { P-FSH/exposure } \\
\text { P-FSH/age } \\
\text { P-FSH/exposure, age, } t_{x y . z}\end{array}$ & $\begin{array}{l}-0 \cdot 27^{\star \star} \\
0 \cdot 37^{\star \star \star} \\
(0 \cdot 17)\end{array}$ & $\begin{array}{l}-0 \cdot 18 \\
0 \cdot 32^{\star \star} \\
(0 \cdot 08)\end{array}$ \\
\hline $\begin{array}{l}\text { P-PRL/exposure } \\
\text { P-PRL/age } \\
\text { P-PRL/exposure, age, } t_{x y . z}\end{array}$ & $\begin{array}{c}0 \cdot 13 \\
-0 \cdot 28^{\star \star} \\
(0.04)\end{array}$ & $\begin{array}{c}0.14 \\
-0 \cdot 26^{\star} \\
(0 \cdot 12)\end{array}$ \\
\hline $\begin{array}{l}\text { P-Test/exposure } \\
\text { P-Test/age } \\
\text { P-Test/exposure, age, } t_{\mathrm{xy} . z}\end{array}$ & $\begin{array}{l}-0 \cdot 25^{\star} \\
0 \cdot 07 \\
(0 \cdot 24)\end{array}$ & $\begin{array}{r}-0.29 \star \\
0.003 \\
(0.30)\end{array}$ \\
\hline
\end{tabular}

${ }^{\star} p<0.05 ;{ }^{\star \star} p<0.01 ;{ }^{\star \star \star} p<0.001$.

$\dagger$ In the "restricted group" heavy alcohol consumers are excluded. 


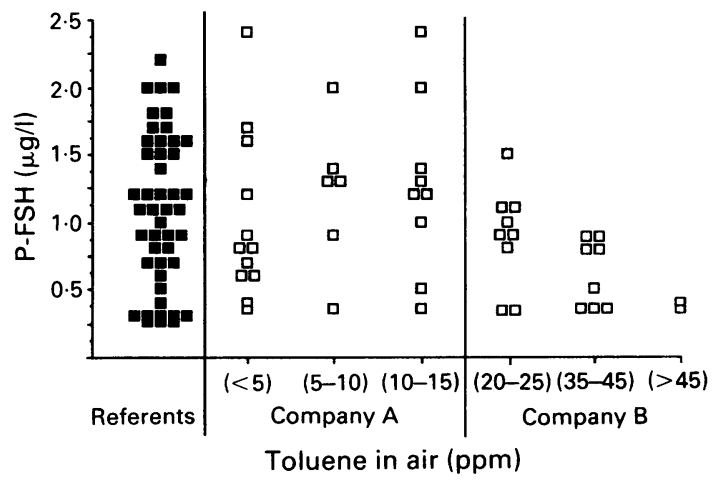

Figure 3 Plasma concentrations of follicle stimulating hormone ( $P-F S H)$ for referents and subjects exposed to toluene.

ETHANOL CONSUMPTION

Exclusion of nine subjects with a history of heavy drinking from the exposed group did not affect the relations between P-LH and P-Test on the one hand and exposure on the other (table 4). There was no longer any statistically significant correlation between $\mathrm{P}-\mathrm{FSH}$ and exposure in the exposed group when so restricted.

\section{LIVER FUNCTION}

The exposed subjects had higher S-ALP activity $(p=0.0005)$ than the referents (table 5). The S-GT activity was also slightly higher among the printers ( $\mathrm{p}=0.05$ ). Only the difference in S-ALP activity was still significant ( $p=0.002$ ), when heavy drinkers were excluded from the exposed group. No statistically significant differences were found between exposed workers and referents in S-ASAT and SALAT activities. The S-ALAT activity correlated significantly with present exposure concentrations

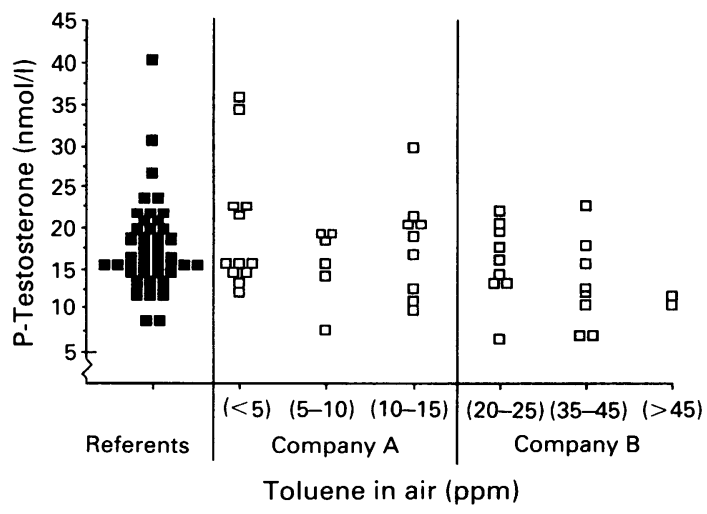

Figure 4 Plasma testosterone concentrations for referents and subjects exposed to toluene.
Table 5 Results from tests of liver function (medians ranges)

\begin{tabular}{|c|c|c|c|}
\hline & \multirow[b]{2}{*}{$\begin{array}{l}\text { Referents } \\
(n=46)\end{array}$} & \multicolumn{2}{|c|}{ Exposed group } \\
\hline & & $\underset{(n=47)}{A l l}$ & $\begin{array}{l}\text { Restricted } \\
(n=38)\end{array}$ \\
\hline $\begin{array}{l}\text { S-Bilirubin } \\
(\mu \mathrm{mol} / 1) \\
\text { S-ALP } \\
(\mu \text { kat } / 1) \\
\text { S-GT } \\
(\mu \text { kat } / 1) \\
\text { S-ASAT } \\
(\mu \text { kat } / 1) \\
\text { S-ALAT } \\
(\mu \text { kat } / 1)\end{array}$ & $\begin{array}{l}12 \\
(4-55) \\
2 \cdot 8^{13} \\
(1 \cdot 8-4 \cdot 6) \\
0 \cdot 4^{2} \\
(0 \cdot 2-1 \cdot 7) \\
0 \cdot 4 \\
(0 \cdot 3-0 \cdot 6) \\
0 \cdot 3 \\
(0 \cdot 1-0 \cdot 7)\end{array}$ & $\begin{array}{l}12 \\
(6-33) \\
3 \cdot 4^{1} \\
(1 \cdot 6-6 \cdot 3) \\
0 \cdot 4^{2} \\
(0 \cdot 2-4 \cdot 8) \\
0 \cdot 4 \\
(0 \cdot 2-1 \cdot 7) \\
0 \cdot 4 \\
(0 \cdot 1-1 \cdot 8)\end{array}$ & $\begin{array}{l}12 \\
(6-33) \\
3 \cdot 3^{3} \\
(2 \cdot 1-4 \cdot 9) \\
0 \cdot 4^{2} \\
(0 \cdot 2-2 \cdot 0) \\
0 \cdot 4 \\
(0 \cdot 2-0 \cdot 6) \\
0 \cdot 4 \\
(0 \cdot 1-1 \cdot 0)\end{array}$ \\
\hline
\end{tabular}

${ }^{1} p=0.0005 ;{ }^{2} p=0.05 ;{ }^{3} p=0.002$.

Results are medians; ranges in parentheses.

Heavy alcohol consumers are excluded from the "restricted group".

(tau $=0.22, p=0.03$ ) when heavy drinkers were included in the group; however, this correlation disappeared when they were excluded. No other correlations between present exposure and tests of liver function were found. No associations existed between cumulative exposure and tests of liver function.

\section{Discussion}

The evaluation of present and past exposure is probably reasonably adequate. The workers were observed during a full work week, and measurements of toluene concentrations in air during that week were fairly extensive. The blood toluene concentrations measured repeatedly pre- and post-shift support the air measurements. ${ }^{12}$ Thus the overall individual index of present exposure is well founded.

The average exposure was well below the Swedish TLV of $80 \mathrm{ppm}$. Although some workers were occasionally exposed to higher concentrations, none had a constant time weighted average (TWA) exposure above the TLV.

The evaluation of past exposure is, of course, less reliable. For the period from the mid 1960s and later, however, the evaluation is fairly well founded. Regarding earlier periods, the estimates may be less accurate, although probably not deviating from the true values by more than a factor of two. Thus the individual estimates of cumulative exposure are probably adequate for the possible error not to be the main explanation of their lack of association with hormone concentrations.

The present data show effects of exposure upon some hormone concentrations, although no statistically significant differences were found in any of the hormone concentrations between the total exposed and referent groups. This may depend upon variations in age and intensity of exposure. Thus younger 
members of the exposed group had significantly lower P-LH, P-FSH, and P-Test than the correspondingly young referents. This may be due to a modifying action of age. As the younger members of the work forces at the two companies were more exposed to toluene than the older ones, it may also be simply an effect of the intensity of exposure, which varied considerably within the exposed group. This problem was tackled by analysis of partial rank correlation coefficients. For P-FSH, there was an influence of age, which indicates effect modification. For P-LH and P-Test, the main association was with exposure; age was less important.

A difference was found in tests for liver function between exposed subjects and referents. The difference in S-GT activity could hardly be attributed to exposure to toluene. ${ }^{18}$ More likely, it indicates differences in drinking habits between the two groups. As chronic alcohol consumption could produce effects on hormones similar to those we found,$^{19}$ alcohol could be a confounding factor. The observed effects on P-LH and P-Test were not affected, however, by the exclusion of heavy drinkers, and, therefore, we believe that these effects are related to exposure to toluene.

No associations were found between the effects seen and cumulative exposure, whereas a relation did exist with present exposure, which may indicate that these toluene related effects are acute or subacute ones. We do not know whether they are reversible.

The combination of low P-LH and P-Test with rising exposure indicates an effect somewhere in the CNS or hypothalamus-pituitary axis. A primary effect on the testes, with a primary decrease in $P$-Test, would result in rising P-LH and P-FSH (a lesion in the cortex with secondary effects on the hypothalamus-pituitary axis cannot be ruled out).

Exposure to another organic solvent, styrene, has been associated with neuroendocrine effects ${ }^{20}$ mainly on PRL concentrations in occupationally exposed women. Toluene has been reported to cause menstrual disturbances ${ }^{21}$ which might be in accordance with our findings. We have not seen any other reports on endocrine effects in occupationally exposed humans; however, it is well known, that certain drugs such as marijuana, and barbiturates affect the hypothalamic nervous pathways that control the secretion of gonadotrophins. ${ }^{19}$

Some organic solvents, including toluene, have been shown to affect dopamine and noradrenaline turnover within various parts of the hypothalamus. ${ }^{52}$ Several hormones, including FSH, LH, and PRL, are controlled by dopaminergic systems. An interference of toluene or of its metabolites with the activity of these systems might explain the effects. ${ }^{23}$

The exposed workers had higher S-ALP activity than the referents and this difference still existed when heavy drinkers were excluded from the exposed group. Thus there is a possibility that this increase might be associated with exposure to toluene. This is in accordance with another study on the effects of exposure to a mixture of organic solvents ${ }^{24}$ in which toluene was the most frequently occurring, and where the exposed workers had significantly higher S-ALP.

The study was supported by a grant from the Swedish Work Environment Fund. The Staff of the Department of Occupational Medicine at Malmö General Hospital made the scrupulous clinical examinations of the printers. Valuable technical assistance was given by Ms Ingalilll Sandell $R N$ and Ms Eva Jonasson RN.

1 Benignus VA. Health effects of toluene: a review. Neurotoxicology $1981 ; 2: 567-88$.

2 World Health Organisation. Environmental Health Criteria 52 Toluene. Geneva: WHO, 1985.

3 World Health Organisation. Chronic effects of organic solvents on the central nervous system and diagnostic criteria. Copenhagen: WHO, 1985.

4 Schaumburg HH, Spencer PS. Environmental hydrocarbons produce degeneration in cat hypothalamus and optic tract. Science 1978;199:199-200.

5 Andersson K, Fuxe K, Toftgård R, Nilsen OD, Eneroth $P$, Gustafsson JA. Toluene-induced activation of certain hypothalamic and median eminence catecholamine nerve terminal systems of the male rat and its effects on anterior pituitary hormone secretion. Toxicol Lett 1980;5:393-8.

6 Andersson K, Fuxe K, Nilsen OG, Toftgärd R, Eneroth $P$ Gustafsson JÅ. Production of discrete changes in dopamine and noradrenaline levels and turnover in various parts of the rat brain following exposure to xylene, ortho-, meta- and paraxylene, and ethylbenzene. Toxicol Appl Pharmacol 1981; 60:535-48.

7 Rubinstein L, Sawyer CH. Role of catecholamines in stimulating the release of pituitary ovulatory hormone(s) in the rat. Endocrinology 1979;86:988-95.

8 Andersson K, Fuxe K, Eneroth P, Nyberg F, Roos P. Rat prolactin and hypothalamic catecholamine nerve terminal systems. Evidence for rapid and discrete increases in dopamine and noradrenaline turnover in the hypophysectomized male rat. Eur J Pharmacol 1981;76:261-5.

9 Andersson K, Fuxe K, Agnati LF, Eneroth P, Camurri M. Luteinizing hormone-releasing hormone increases dopamine turnover in the lateral palisade zone of the median eminence and reduces noradrenaline turnover in the nuc. preopticus medialis of the hypophysectomized male rat. Neurosci Lett 1984;45:253-8.

10 Andersson K, Eneroth P. Thyroidectomy and central catecholamine neurons of the male rat. Evidence for the existence of an inhibitory dopaminergic mechanism in the external layer of the median eminence and for a facilitatory noradrenergic mechanism in the paraventricular hypohalamic nucleus regulating TSH secretion. Neuroendocrinology 1987;45:14-27.

11 Ovrum $P$. The sampling of organic solvent vapors in air by motor-powered syringes. Am Ind Hyg Assoc J 1986;47:650-4.

12 Nise G, Orbaek P. Toluene in venous blood during and after work in rotogravure printing. Int Arch Occup Environ Health 1988;60:31-5.

13 Brugnone F, de Rosa E, Perbellini L, Bartolucci GB. Toluene concentrations in the blood and alveolar air of workers during the work shift and the morning after. Br J Ind Med 1986;43: $56-61$.

14 Svensson B-G, Nise G, Englander V, Attewell R, Skerfving S, Möller $T$. Deaths and tumours among rotogravure printers exposed to toluene. Br J Ind Med 1990;47:372-9.

15 Thorell JI, Larson SM. Radioimmunoassay and related techniques. Methodology and clinical applications. St Louis: The C V Mosby Company, 1978. 
16 Jeppsson S, Rannevik G. Studies on the gonadotropin response after administration of $\mathrm{LH} / \mathrm{FSH}$-releasing hormone (LRH) during pregnancy and after therapeutic abortion in the second trimester. Am J Obstet Gynecol 1976;125:484-90.

17 Siegle S. Nonparametric statistics for the behavioral sciences. Tokyo. McGraw-Hill Kokakusha Ltd, 1956.

18 Waldron HA, Cherry N, Venables H. Solvent exposure and liver function. Lancet 1982;ii:1276.

19 Smith CG. Reproductive toxicity: hypothalamic-pituitary Mechanisms. Am J Ind Med 1983;4:107-12.

20 Mutti A, Vescovi PP, Falzoi M, Arfini G, Valenti G, Franchini I Neuroendocrine effects of styrene on occupationally exposed workers. Scand J Work Environ Health 1984;10:225-8.

21 Michon S. Disturbance of menstruation in woman working in an atmosphere polluted with aromatic hydrocarbons. Pol Tyg Lek 1965;20:1547-649. (In Polish.)
22 Andersson K, Nilsen OG, Toftgård R, et al. Increased amine turnover in several hypothalamic noradrenaline nerve terminal systems and changes in prolactin secretion in the male rat by exposure to various concentrations of toluene. Neurotoxicology 1983;4:43-56.

23 Mutti A, Franchini I. Toxicity of metabolites to dopaminergic systems and the behavioural effects of organic solvents (editorial). Br J Ind Med 1987;44:721-3.

24 Elofsson S-A, Gamberale F, Hindmarsk T, et al. Exposure to organic solvents. A cross-sectional epidemiological investigation on occupationally exposed car and industrial spray painters with special reference to the nervous system. Scand $J$ Work Environ Health 1980;6:239-73.

Accepted 7 October 1991
All manuscripts submitted to the $\mathrm{Br} J$ Ind Med should conform to the uniform requirements for manuscripts submitted to biomedical journals (known as the Vancouver style).

The $B r J$ Ind Med, together with many other international biomedical journals, has agreed to accept articles prepared in accordance with the Vancouver style. The style (described in full in $\mathrm{Br}$ Med J, 24 February 1979, p 532) is intended to standardise requirements for authors.

References should be numbered consecutively in the order in which they are first mentioned in the text by Arabic numerals above the line on each occasion the reference is cited (Manson ${ }^{1}$ confirmed other reports $\left.{ }^{2-5} \ldots\right)$. In future references to papers submitted to the $B r J$ Ind Med should include: the names of all authors if there are six or less or, if there are more, the first three followed by et al; the title of journal articles or book chapters; the titles of journals abbreviated according to the style of Index Medicus; and the first and final page numbers of the article or chapter.

Examples of common forms of references are:

1 International Steering Committee of Medical Editors. Uniform requirements for manuscripts submitted to biomedical journals. Br Med J 1979;1:532-5.

2 Soter NA, Wasserman SI, Austen KF. Cold urticaria: release into the circulation of histamine and eosino-phil chemotactic factor of anaphylaxis during cold challenge. N Engl J Med 1976;294:687-90.

3 Weinstein L, Swartz MN. Pathogenic properties of invading micro-organisms. In: Sodeman WA Jr, Sodeman WA eds. Pathologic physiology: mechanisms of disease. Philadelphia: W B Saunders, 1974:457-72. 